Published in final edited form as:

ACS Biomater Sci Eng. 2016 May 9; 2(5): 838-844. doi:10.1021/acsbiomaterials.6b00061.

\title{
High Aspect Ratio Nanotubes Formed by Tobacco Mosaic Virus for Delivery of Photodynamic Agents Targeting Melanoma
}

\author{
Karin L. Lee ${ }^{\dagger}$, Bradley L. Carpenter ${ }^{\ddagger}$, Amy M. Wen ${ }^{\dagger}$, Reza A. Ghiladi ${ }^{\ddagger}$, and Nicole F. \\ Steinmetz ${ }^{\dagger},,, \|, \perp, \#,{ }^{*}$ \\ tDepartment of Biomedical Engineering, Schools of Medicine and Engineering, Case Western \\ Reserve University, Cleveland, Ohio 44106, United States \\ $\S$ Department of Radiology, Schools of Medicine and Engineering, Case Western Reserve \\ University, Cleveland, Ohio 44106, United States \\ "Department of Materials Science and Engineering, Schools of Medicine and Engineering, Case \\ Western Reserve University, Cleveland, Ohio 44106, United States \\ ${ }^{\perp}$ Department of Macromolecular Science and Engineering, Schools of Medicine and Engineering, \\ Case Western Reserve University, Cleveland, Ohio 44106, United States \\ \#Case Comprehensive Cancer Center, Schools of Medicine and Engineering, Case Western \\ Reserve University, Cleveland, Ohio 44106, United States \\ ‡Department of Chemistry, North Carolina State University, Raleigh, North Carolina 27695, United \\ States
}

\begin{abstract}
Melanoma is a highly aggressive cancer that is unresponsive to many traditional therapies.

Recently, photodynamic therapy has shown promise in its treatment as an adjuvant therapy.

However, conventional photosensitizers are limited by poor solubility and limited accumulation within target tissue. Here, we report the delivery of a porphyrin-based photosensitizer encapsulated within a plant viral nanoparticle. Specifically, we make use of the hollow, high aspect ratio nanotubes formed by the nucleoprotein components of tobacco mosaic virus (TMV) to encapsulate the drug for delivery and targeting of cancer cells. The cationic photosensitizer was successfully and stably loaded into the interior channel of TMV via electrostatic interactions. Cell uptake and efficacy were evaluated using a model of melanoma. The resulting TMVphotosensitizer exhibited improved cell uptake and efficacy when compared to free photosensitizer, making it a promising platform for improved therapy of melanoma.
\end{abstract}

\section{Graphical Abstract}

\footnotetext{
*Corresponding Author. nicole.steinmetz@case.edu. ASSOCIATED CONTENT

Supporting Information

The Supporting Information is available free of charge on the ACS Publications website at DOI: 10.1021/acsbiomaterials.6b00061.

Plot of stability of Zn-EpPorTMV over time (PDF)

The authors declare no competing financial interest.
} 


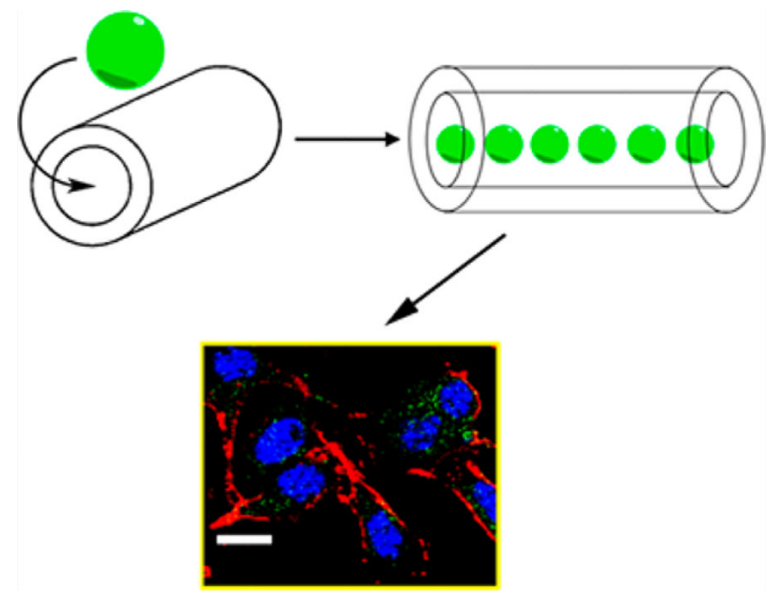

\section{Keywords}

viral nanoparticles; tobacco mosaic virus; photodynamic therapy; melanoma

\section{INTRODUCTION}

Melanoma, which arises from melanocytes, is a highly aggressive cancer, and although it accounts for only $4 \%$ of skin cancers, it results in approximately $79 \%$ of skin cancer related deaths. ${ }^{1}$ Even when diagnosed early, approximately $20 \%$ of cases cannot be treated using surgical resection. ${ }^{1}$ Additionally, it is unresponsive to many known therapies. ${ }^{2,3}$ Recent data suggest that photodynamic therapy (PDT) provides a novel, efficacious regime for treating melanoma that may hold potential as an adjuvant therapy for all stages of melanoma. ${ }^{1,3-7}$

PDT is an emerging technique for cancer therapy, and unlike many current cancer therapies, PDT consists of three nontoxic components: a photosensitizer (PS), light, and oxygen. ${ }^{8}$ Only when all three components are present is cell killing induced, therefore making it a safe alternative to other cancer treatments, such as chemotherapy and radiotherapy. ${ }^{8}$ Specifically, when light of a certain wavelength activates the photosensitizer in the presence of oxygen, it causes a photochemical reaction that generates reactive oxygen species (ROS). These ROS lead to oxidative stress of biomolecules to damage organelle function, leading to apoptosis and necrosis. ${ }^{9}$ In addition to directly impacting tumor cells, PDT has been shown to cause damage in the tumor microenvironment. ROS cause damage to the tumor vasculature, which can prevent the necessary oxygen and nutrient exchange, therefore enhancing the overall treatment efficacy. ${ }^{10}$ Additionally, PDT has been shown to elicit an antitumor immune response at the site of administration, further potentiating the therapy. ${ }^{10}$

A few photosensitizers have received FDA approval for clinical use; these include the photosensitizer Photofrin (porfimer sodium) for use in esophageal and non-small cell lung cancers. ${ }^{11}$ Aminolevulinic acid (AVA) has been approved for precancerous Barrett's esophagus. ${ }^{12}$ The development pipeline is rapidly expanding with numerous clinical and preclinical trials investigating novel photosensitizers and their use in PDT targeting various 
cancers. These include head and neck, skin, cervical, lung, gastric, prostate, and breast cancers. ${ }^{11,13-19}$

Nevertheless, translational challenges exist: photosensitizers are delivered intravenously, but have poor bioavailability and low accumulation in the tumor tissue. To ensure that appropriate amounts reach the site of disease, large amounts have to be delivered, resulting in dispersal of the photosensitizer throughout the body. As a result, patients have to avoid sunlight for four to six weeks following treatment. Additionally, many photosensitizers are hydrophobic, making them insoluble in physiological conditions. ${ }^{18}$ Nanoparticle platform technologies hold promise to enhance solubility, bioavailability, and biodistribution allowing drug targeting to the site of disease; the potential of nanoparticle delivery of photosensitizers has been recognized. ${ }^{20}$ Nanoparticles can carry large quantities of photosensitizers and enhance cell uptake and therefore cargo delivery. Nanoparticles have a propensity to accumulate in tumors through passive homing based on the enhanced permeability and retention effect, or they can be engineered with targeting ligands to impart tissue specificity. $^{21}$

Toward the goal to develop a nanoparticle PDT technology, we turned toward a biologyinspired platform, specifically using the nanocarriers formed by plant viruses as the delivery system. Plant virus-based scaffolds can be produced inexpensively at high yields in plants. The protein-based nanoparticles are highly monodisperse, and their structures are known to atomic resolution. Viruses have naturally evolved to deliver cargos, but plant viruses are noninfectious toward mammals. They are biocompatible and biodegradable and therefore offer favorable properties for in vivo medical applications. ${ }^{22-24}$

In this work, we focused on the nucleoprotein components formed by the tobacco mosaic virus (TMV). TMV is a $300 \times 18 \mathrm{~nm}$ hollow rod, with a $4 \mathrm{~nm}$ wide interior channel. Its structure is known to atomic resolution, and the chemistries for modifying the coat protein have been well established. ${ }^{25,26}$ The in vitro and in vivo properties of TMV have been well characterized: TMV exhibits shape-mediated enhanced tumor homing and penetration compared to spherical viruses. ${ }^{27-30}$ Therefore, we reasoned that TMV would be a suitable carrier for delivery of photosensitizers. Specifically, we sought to develop TMV as a carrier for a porphyrin-based photosensitizer: 5-(4-ethynylphenyl)-10,15,20-tris(4-methylpyridin-4ium-1-yl)porphyrin-zinc(II) triiodide (Zn-EpPor). ${ }^{31}$

Zn-EpPor is a cationic porphyrin (Figure 1A) previously used in antimicrobial photodynamic inactivation (aPDI) studies. It has been successfully conjugated to cellulose, both as nanocrystals and as fibers, to create photoactivatable materials that were shown to be effective against various strains of drug resistant bacteria, including multidrug-resistant Acinetobacter baumannii (MDRAB), methicillin-resistant Staphylococcus aureus (MRSA), and vancomycin-resistant Enterococcus faecium, as well as effective against viruses, including dengue-1, influenza A, and human adenovirus-5. ${ }^{31-33}$ Unlike other porphyrinbased PDT molecules, Zn-EpPor has an overall cationic charge and contains a zinc molecule within the porphyrin ring. ${ }^{31}$ Recent work indicates that the presence of a cationic charge enhances accumulation within the mitochondria, while the presence of zinc stabilizes the porphyrin ring, both of which improve therapeutic efficacy. ${ }^{14} \mathrm{Zn}$-EpPor is unique in that it 
contains both of these characteristics, making it a suitable candidate for a proof-of-principle study using a nanoparticle strategy targeting cancer. We demonstrate the nanoparticle formulation of Zn-EpPor and its use in cancer PDT. Specifically, Zn-EpPor was encapsulated into the central TMV channel, allowing for increased therapeutic delivery and efficacy. As a proof-of-concept, melanoma was studied as the test bed.

\section{EXPERIMENTAL METHODS}

\section{Zn-EpPor Synthesis}

5-(4-Ethynylphenyl)-10,15,20-tris(4-methylpyridin-4-ium-1-yl)porphyrin-zinc(II) triiodide (Zn-EpPor) was synthesized in a four-step procedure, as described previously. ${ }^{31}$

\section{TMV Propagation}

TMV was propagated in Nicotiana benthamiana plants. Infection was carried out using 100 $\mathrm{ng} \mathrm{mL} \mathrm{m}^{-1} \mathrm{TMV}$ in $0.1 \mathrm{M}$ potassium phosphate (KP) buffer ( $\mathrm{pH} 7.0$ ); to promote the infectious process leaves were dusted with carborundum prior to mechanical inoculation. Leaves were collected 18-20 days postinfection, and TMV was isolated using established procedures ${ }^{34}$ Virus concentration was determined by UV/visible spectroscopy $\left(\varepsilon_{\mathrm{TMV}}=3.0\right.$ $\mathrm{mL} \mathrm{mg}^{-1} \mathrm{~cm}^{-1}$ ).

\section{Zn-EpPor Loading into TMV}

Both wild-type TMV and a TMV-Lys mutant $\left(\mathrm{TMV}_{\mathrm{Lys}} ; \mathrm{T} 158 \mathrm{~K}\right)^{35}$ were investigated for modification with $\mathrm{Zn}$-EpPor. $\mathrm{TMV}_{\mathrm{Lys}}$ was modified with an azide functional handle, followed by click chemistry using previously established methods. ${ }^{26}$ Alternatively, TMV (1 $\mathrm{mg} \mathrm{mL}^{-1}$ final concentration, in $0.01 \mathrm{M} \mathrm{KP}$ buffer, $\mathrm{pH}$ 7.8) was incubated with a 6000 molar excess of Zn-EpPor, with agitation, overnight. TMV-Zn-EpPor was purified over a $40 \%$ $(\mathrm{w} / \mathrm{v})$ sucrose cushion using ultracentrifugation at $212000 \mathrm{~g}$ for $3 \mathrm{~h}$ at $4{ }^{\circ} \mathrm{C}$. Zn-EpPor-loaded TMV (Zn-EpPorTMV) nanoparticles were analyzed using a combination of UV/visible spectroscopy, inductively coupled plasma optical emission spectroscopy (ICP-OES), transmission electron microscopy (TEM), and size exclusion chromatography (SEC); see below. To confirm that Zn-EpPor was indeed loaded into the central channel of TMV, chemically modified TMV was utilized in which either exterior or interior surface reactive groups were modified with alkynes to shield surface charges; the bioconjugation protocols were as previously described. ${ }^{25}$

\section{UV/Visible Spectroscopy}

The number of Zn-EpPor molecules per TMV nanoparticle was determined using both UV/ visible spectroscopy and ICP-OES (see below). Using the NanoDrop 2000 spectrophotometer, Zn-EpPor loading was determined using the Beer-Lambert law and the Zn-EpPor $\left(\varepsilon_{450 \mathrm{~nm}}=195,000 \mathrm{M}^{-1} \mathrm{~cm}^{-1}\right)$ and TMV $\left(\varepsilon_{260 \mathrm{~nm}}=3 \mathrm{~mL} \mathrm{mg}^{-1} \mathrm{~cm}^{-1}\right)$ molar absorptivity coefficients. 


\section{Inductively Coupled Plasma Optical Emission Spectroscopy (ICP-OES)}

As a complementary method, ICP-OES was used to determine the number of Zn-EpPor molecules per TMV nanoparticle. This was achieved by quantification of the $\mathrm{Zn}$ :TMV ratio. To release $\mathrm{Zn}$ cations from the porphyrin backbone, $\mathrm{Zn}$-EpPor TMV was incubated in $1 \mathrm{M} \mathrm{HCl}$ for $2 \mathrm{~h}$ at $60{ }^{\circ} \mathrm{C}$. Following incubation, the solution was diluted to $0.1 \mathrm{mg} \mathrm{mL}^{-1} \mathrm{TMV}$ and analyzed immediately at $\lambda=202.548$. The $\mathrm{Zn}$ concentration was determined using a calibration standard curve.

\section{Size Exclusion Chromatography (SEC)}

Zn-EpPor TMV particles were analyzed by SEC using a Superose6 column and ÄKTA Explorer chromatography system (GE Healthcare). Samples (100 $\mu \mathrm{L}, 1 \mathrm{mg} \mathrm{mL}^{-1}$ ) were analyzed at a flow rate of $0.5 \mathrm{~mL} \mathrm{~min}^{-1}$ in $0.01 \mathrm{M}$ potassium phosphate buffer, $\mathrm{pH} 7$.

\section{Transmission Electron Microscopy}

Transmission electron microscopy (TEM) was performed before and after light illumination to assess the stability of the drug delivery system. $\mathrm{Zn}$-EpPorTMV $\left(1 \mathrm{mg} \mathrm{mL}^{-1}\right)$ was illuminated in a rectangle $(10.5 \mathrm{~cm} \times 11 \mathrm{~cm})$ under white light from a Vivitek D950HD projector $\left(\sim 10 \mathrm{~mW} \mathrm{~cm}{ }^{-2}\right.$ at $\left.430 \mathrm{~nm}\right)$ for $30 \min \left(18.1 \mathrm{~J} \mathrm{~cm}^{-2}\right.$ at $\left.430 \mathrm{~nm}\right)$. Control samples were kept in the dark for $30 \mathrm{~min}$. Samples were then diluted to $0.1 \mathrm{mg} \mathrm{mL}^{-1}$, placed on carbon-coated copper grids, and negatively stained with $2 \%(\mathrm{w} / \mathrm{v})$ uranyl acetate for $5 \mathrm{~min}$ prior to imaging. Samples were analyzed using a Zeiss Libra 200FE transmission electron microscope operated at $200 \mathrm{kV}$.

\section{Tissue Culture}

B16F10 melanoma cells were purchased from ATCC, maintained in Dulbecco's modified Eagle's medium (DMEM) (Invitrogen) supplemented with 10\% (v/v) fetal bovine serum (FBS) (Atlanta Biologicals) and 1\% (v/v) penicillin-streptomycin (Invitrogen), and grown at $37^{\circ} \mathrm{C}$ and $5 \% \mathrm{CO}_{2}$.

\section{Flow Cytometry}

Confluent B16F10 cells were removed using Hanks'-based cell dissociation buffer (ThermoFisher) and added to 96-well v-bottom plates ( $200 \mu \mathrm{L} / \mathrm{well}, 2.5 \times 10^{6}$ cells $\left./ \mathrm{mL}\right)$. Native TMV, free Zn-EpPor, or drug-loaded Zn-EpPor TMV was added to wells $\left(1 \times 10^{5}\right.$ particles/cell) in triplicate and incubated for $8 \mathrm{~h}$ at $37^{\circ} \mathrm{C}$ and $5 \% \mathrm{CO}_{2}$. Following incubation, cells were washed 2 times in FACS buffer (1 mM EDTA, 25 mM HEPES, 1\% (v/v) FBS in PBS, pH 7.0) and fixed in 2\% (v/v) paraformaldehyde in FACS buffer for $10 \mathrm{~min}$ at room temperature. Cells were washed 2 times, then resuspended in FACS buffer and analyzed on a BD FACSAria flow cytometer. Live cells were gated, and 10,000 events were recorded; all experiments were carried out in triplicate. Data were analyzed on FlowJo 8.6.3 software.

\section{Confocal Microscopy}

Confluent B16F10 cells were removed using $0.05 \%$ (w/v) trypsin-EDTA and added to 24well untreated plates with coverslips on the bottom $\left(500 \mu \mathrm{L} / \mathrm{well}, 5 \times 10^{4}\right.$ cells $\left./ \mathrm{mL}\right)$; cells were grown overnight. Zn-EpPor TMV was added to wells $\left(1 \times 10^{7}\right.$ particles/cell $)$ and 
incubated for $8 \mathrm{~h}$ at $37{ }^{\circ} \mathrm{C}$ and $5 \% \mathrm{CO}_{2}$. Following incubation, cells were fixed in DPBS containing $5 \%(\mathrm{v} / \mathrm{v})$ paraformaldehyde and $0.3 \%(\mathrm{v} / \mathrm{v})$ glutaraldehyde for $10 \mathrm{~min}$ at room temperature. Cell membranes were stained with wheat-germ agglutinin (WGA) conjugated to AlexaFluor488 (WGA-A488, Invitrogen) using $1 \mu \mathrm{g} \mathrm{mL}^{-1}$ WGA-A488 in 5\% (v/v) goat serum in DPBS for $45 \mathrm{~min}$ at room temperature. Cells were washed 3 times with DPBS in between each step. Coverslips were mounted onto slides using Fluoroshield with DAPI (Sigma) and sealed with nail polish. Slides were imaged using an Olympus FluoView FV1000 confocal laser scanning microscope, and the data were processed in ImageJ 1.47d (http://imagej.nih.gov/ij).

\section{Cell Viability}

Cell viability was assayed using MTT and LIVE/DEAD assays. Confluent cells were removed using $0.05 \%(w / v)$ trypsin-EDTA, added to 96-well plates (100 $\mu \mathrm{L} /$ well, $2 \times 10^{4}$ cells $/ \mathrm{mL}$ ), and grown overnight. Native TMV, drug loaded Zn-EpPorTMV, or free Zn-EpPor was added to cells using $0.025,0.05,0.1,0.25,0.5,1.0$, and $5.0 \mu \mathrm{M} \mathrm{Zn-EpPor;} \mathrm{cells} \mathrm{were}$ incubated for $8 \mathrm{~h}$ at $37{ }^{\circ} \mathrm{C}$ and $5 \% \mathrm{CO}_{2}$. Assays were done in triplicate and repeated at least twice. Following incubation, cells were washed twice to remove unbound drug and drug carriers, and then $100 \mu \mathrm{L}$ of medium was added. Samples were illuminated in a rectangle $(10.5 \mathrm{~cm} \times 11 \mathrm{~cm})$ under white light from a Vivitek D950HD projector $\left(\sim 10 \mathrm{~mW} \mathrm{~cm}{ }^{-2}\right.$ at $430 \mathrm{~nm}$ ) for $30 \mathrm{~min}\left(18.1 \mathrm{~J} \mathrm{~cm}^{-2}\right.$ at $\left.430 \mathrm{~nm}\right)$. Control samples were kept in the dark for 30 min. After illumination, plates were incubated at $37^{\circ} \mathrm{C}$ and $5 \% \mathrm{CO}_{2}$ for $48 \mathrm{~h}$. Cell viability was assessed using an MTT cell proliferation assay (ATCC); the procedure was as per manufacturer's recommendation. Alternatively, cell viability and cytotoxicity was determined using the live life in LIVE/DEAD Viability/Cytotoxicity Kit for mammalian cells (ThermoFisher). The staining procedure was as per manufacturer's recommendation. Plates were imaged on a Zeiss Axio Observer Z1 motorized FL inverted microscope. Images were analyzed for percentage cell viability using ImageJ $1.47 \mathrm{~d}$ (http://imagej.nih.gov/ij).

\section{RESULTS}

\section{Zn-EpPorTMV Encapsulation and Characterization}

Tobacco mosaic virus (TMV) was produced in and purified from Nicotiana benthamiana plants as previously described. ${ }^{25}$ The nucleoprotein components of TMV form a hollow cylinder measuring $300 \times 18 \mathrm{~nm}$ with a $4 \mathrm{~nm}$ wide interior channel. Each TMV particle is composed of 2,130 identical copies of a coat protein, each containing two solvent-exposed glutamic acids (Glu97, Glu106) on the interior surface and a tyrosine residue (Tyr139) on the exterior (Figure 1A). In this study, a lysine-added mutant was also considered $\left(\mathrm{TMV}_{\mathrm{Lys}}\right.$, T158K) that also offers an amine ligation handle on the solvent-exposed exterior surface (Figure 1A) ${ }^{35}$ Two drug loading strategies were considered: covalent conjugation of $\mathrm{Zn}$ EpPor to the aforementioned amino acid side chains ${ }^{26}$ or noncovalent drug loading through electrostatic interactions, as we recently described. ${ }^{36}$

The drug candidate, $\mathrm{Zn}$-EpPor, was designed and synthesized with an alkyne handle (Figure 1A) for covalent conjugation to an azide-bearing motif using the $\mathrm{Cu}(\mathrm{I})$-catalyzed HuisgenMeldal-Sharpless 1,3-dipolar cycloaddition reaction. In brief, $\mathrm{TMV}_{\text {Lys }}$ was first modified 
with an azide functional handle using $N$-hydroxysuccinimide (NHS) ester-PEG $\mathrm{P}_{4}$-azide, followed by the click reaction using $\mathrm{Zn}$-EpPor and reaction conditions as previously described. ${ }^{26}$ However, any conjugation attempts resulted in extensive aggregation and loss of the sample, and therefore were not further pursued.

Instead, Zn-EpPor was loaded into TMV making use of the chemically distinct exterior and interior microenvironments. The interior channel of TMV is lined with a high density of negative charges from solvent-exposed glutamic acids Glu97 and Glu106 (Figure 1A). We hypothesized that the positively charged drug candidate Zn-EpPor carrying 3 positive charges, one at each of the methylpyridinium side chains, could be loaded into the central channel of TMV based on charge-charge interactions. Zn-EpPor loading was carried out under slightly alkaline conditions ( $\mathrm{pH}$ 7.8) to promote deprotonation of the carboxylic acids and therefore electrostatic complexation with Zn-EpPor (Zn-EpPor was used at a 6000-fold molar excess to TMV). The reaction was allowed to proceed overnight, and then excess $\mathrm{Zn}$ EpPor was removed using ultracentrifugation (Figure 1B). To confirm whether loading occurred and whether free Zn-EpPor was removed following centrifugation, Zn-Ep-Por TMV was analyzed using size exclusion chromatography (Figure 1D). TMV showed the characteristic elution profiles at $8 \mathrm{~mL}$ using the Superose6 column and ÄKTA purifier; broken particles or free coat proteins were not detectable. The coelution of the $260 \mathrm{~nm}$ (RNA component), $280 \mathrm{~nm}$ (protein component), and $450 \mathrm{~nm}$ (Zn-EpPor specific absorbance) peaks indicates successful loading into TMV. No additional peaks were observed at any of the wavelengths measured, indicating that $\mathrm{Zn}$-EpPorTMV was both intact and void of free $\mathrm{Zn}$-EpPor.

The loading efficiency was quantified using UV/visible spectroscopy and inductively coupled plasma optical emission spectroscopy (ICP-OES) (Figure 1E). Using the BeerLambert law and the TMV- and Zn-EpPor-specific molar absorptivity coefficients $\left(\varepsilon_{\mathrm{TMV}}=\right.$ $3.0 \mathrm{mg} \mathrm{mL}^{-1} \mathrm{~cm}^{-1}$ at $260 \mathrm{~nm} ; \varepsilon_{\mathrm{Zn} \text {-EpPor }}=195,000 \mathrm{M}^{-1} \mathrm{~cm}^{-1}$ at $450 \mathrm{~nm}$ ), the concentrations of TMV and Zn-EpPor in solution and, hence, the ratio of Zn-EpPor:TMV were determined. On average, $800 \mathrm{Zn}$-EpPor were loaded into a TMV particle. The UV/visible spectroscopic method was complemented with ICP-OES measurements to quantify the $\mathrm{Zn}$ loading. The latter method may be considered more accurate, because the porphyrin molar absorptivity coefficient is solvatochromic and may be different in the TMV microenvironment than in free solution. For ICP-OES, zinc was released from $\mathrm{Zn}$-EpPorTMV by incubation at $60{ }^{\circ} \mathrm{C}$ for $2 \mathrm{~h}$ in $1 \mathrm{M} \mathrm{HCl}$. Zinc content was then quantified based on a calibration standard curve. Overall, the data were in good agreement indicating loading of approximately $900 \pm 15 \%$ Zn-EpPor per TMV, which is in agreement with the spatial constraints of the interior channel of TMV. With a $4 \mathrm{~nm}$ interior channel radius, the $300 \mathrm{~nm}$ TMV rod has an interior surface area of approximately $3,770 \mathrm{~nm}^{2}$. Given $900 \mathrm{Zn}$-EpPor loaded into TMV, there is approximately $4.2 \mathrm{~nm}^{2}\left(420 \AA^{2}\right.$ ) available per Zn-EpPor molecule, greater than either the topological polar surface area of approximately $75 \AA^{2}$ or the total molecular area of $235 \AA^{2}$, both calculated from the crystal structure of $\mathrm{Zn}$-EpPor, ${ }^{37}$ indicating that the high loading efficacy seen is highly feasible. Additionally, similar loading was seen with a $2+$ species of platinum drug candidate, phenanthriplatin. 36 
To confirm further that Zn-EpPor was indeed loaded into the interior channel, and not nonspecifically adsorbed on the exterior particle surface, TMV was modified on either the interior (TMV-iAlk) or exterior (TMV-eAlk) surface with alkyne groups to mask charged amino acids. In brief, alkyne handles were attached to either the interior or exterior surfaces of TMV using EDC chemistry to target interior glutamic acids or diazonium salt modification to target the exterior tyrosine residue, using previously established protocols. ${ }^{25}$ Native TMV, TMV-iAlk, and TMV-eAlk were incubated with Zn-EpPor as described above. Following purification, Zn-EpPor loading was quantified using ICP-OES (Figure 1C). Indeed, interior modification of glutamic acid residues with alkynes indicated a decreased loading efficiency resulting in only 50\% loading capacity. A complete reduction in the loading was not observed because it is unlikely that every carboxylic acid was modified with an alkyne, allowing for some electrostatic interactions to remain. On the other hand, exterior modification of TMV showed no difference in Zn-EpPor loading, thus supporting interior loading.

Lastly, we investigated the stability of the Zn-EpPorTMV complex in the dark and after light exposure. Zn-EpPor TMV was kept in the dark or exposed to light—white light from a Vivitek D950HD projector $\left(\sim 10 \mathrm{~mW} \mathrm{~cm}{ }^{-2}\right.$ at $\left.430 \mathrm{~nm}\right)$ under a rectangle $(10.5 \mathrm{~cm} \times 11 \mathrm{~cm})$-for 30 min and then analyzed using transmission electron microscopy (TEM). Light-

exposed Zn-EpPorTMV showed no apparent differences in their macromolecular structure compared to dark controls (Figure 1F), indicating that the treatment with light did not impact the stability of the TMV carrier. Further, we assessed the ability of the TMV carrier to retain the $\mathrm{Zn}$-EpPor compound during storage: $\mathrm{Zn}$-EpPor $\mathrm{TMV}$ was stored at $4{ }^{\circ} \mathrm{C}$ for one month in $0.01 \mathrm{M}$ potassium phosphate buffer, $\mathrm{pH}$ 7.0, and subsequently analyzed using size exclusion chromatography. The elution profiles were consistent with an intact TMV carrier retaining the Zn-EpPor drug candidate (Figure S1).

\section{Cell Uptake and Intracellular Localization of Zn-Ep-PorTMV in B16F10 Melanoma}

Photodynamic therapy (PDT) produces reactive oxygen species (ROS) that have very short half-lives. ${ }^{9,38-40}$ Therefore, to ensure that the ROS are able to exert their mechanism of action, it was important to confirm that Zn-EpPor TMV particles are able to bind to and/or be taken up by the cell; particles that remain in the extracellular space will not be effective for PDT.

Cell binding and uptake of the PDT delivery system was measured using both flow cytometry and confocal microscopy. Cell uptake was measured as a function of Zn-EpPor fluorescence (Figure 2A). Free Zn-EpPor had a mean fluorescence uptake (MFI) of 956, while Zn-EpPorTMV exhibited 40\% enhanced uptake, with a MFI of $1347(p<0.05 \%)$. Unlabeled TMV did show an increase in MFI compared to cells only control, indicating that the fluorescence observed is from the Zn-EpPor. These studies were complemented with confocal microscopy to determine the intracellular fate of Zn-EpPor delivered by TMV. Following an $8 \mathrm{~h}$ incubation of B16F10 cells with $\mathrm{Zn-EpPor}$ TMV particles, cells were fixed and stained with wheat germ agglutinin. Confocal fluorescence microscopy confirmed that $\mathrm{Zn}$-EpPor is both taken up by the cells and also dispersed throughout the cytoplasm (Figure 2B), allowing it to exert its mechanism of action. 


\section{Therapeutic Efficacy of Zn-EpPorTMV Targeting Melanoma}

To evaluate efficacy in vitro, Zn-EpPor TMV was studied in B16F10 melanoma versus free ZnEpPor. Untreated cells and drug-free TMV carrier were used as controls. The TMV concentration was normalized to the drug-loaded concentration and corresponded to the highest amount of TMV used to determine the $\mathrm{IC}_{50}$ curves (Figure $3 \mathrm{~A}$ ). Drug candidates and controls were incubated with B16F10 cells for $8 \mathrm{~h}$, washed, and then exposed to white light from a Vivitek D950HD projector under a rectangle $(10.5 \mathrm{~cm} \times 11 \mathrm{~cm})$ for $30 \mathrm{~min}$. Following illumination, cells were returned to the incubator for $48 \mathrm{~h}$. Cell viability was assessed using an MTT cell viability assay and analyzed using GraphPad Prism. The $\mathrm{IC}_{50}$ values were determined as $0.54 \mu \mathrm{M}$ and $0.24 \mu \mathrm{M}$ for free $\mathrm{Zn}$-EpPor and $\mathrm{Zn}$-EpPorTMV, respectively (Figure 3A). Dark controls did not show any cell killing (data not shown); neither did any of the controls lead to cytotoxicity.

The MTT assay is based on a yellow tetrazolium dye that is reduced to purple formazan via $\mathrm{NAD}(\mathrm{P}) \mathrm{H}$-dependent oxidoreductase enzymes. This reduction is highly dependent on cellular metabolism in the mitochondria and is not high in cells with low cellular metabolic activity. ${ }^{41,42}$ Because photosensitizers are known to impact the functionality of the mitochondria, ${ }^{9}$ the MTT assay may be compromised as a result of impaired mitochondrial activity. Therefore, we also performed LIVE/DEAD cell viability assays to further confirm therapeutic efficacy and cell killing. Cells were incubated with 5.0 $\mu \mathrm{M}$ free Zn-EpPor or Zn-EpPorTMV, or corresponding controls, for $8 \mathrm{~h}$, washed, and illuminated for $30 \mathrm{~min}$. This drug concentration was based on the MTT assay; it is over four times the $\mathrm{IC}_{50}$ value in B16F10 melanoma and should give maximal cell killing. The LIVE/DEAD assay was applied the next day and imaged, and images were analyzed using ImageJ to determine percent cell viability (Figure 3B). All samples kept in the dark, as well as cells only and TMV only controls exposed to light, exhibited high cell viability $(98.32 \pm 0.53 \%)$. On the contrary, cells exposed to both Zn-EpPor or Zn-EpPorTMV and light had 100\% cell killing. It is important to note that, although the MTT assay indicated an increased efficacy for $\mathrm{Zn}$-EpPor TMV versus free $\mathrm{Zn}$-EpPor, the LIVE/DEAD assay in B16F10 cells showed $100 \%$ killing for both samples, as expected based on the $5 \mu \mathrm{M}$ drug concentration.

\section{DISCUSSION}

In this study, we loaded a cationic Zn-based porphyrin photosensitizer (Zn-EpPor) into tobacco mosaic virus (Zn-EpPorTMV) for treatment of aggressive melanoma. We compared cell uptake and cell killing efficacy of Zn-EpPorTMV versus free Zn-EpPor. Flow cytometry data indicate that both free Zn-EpPor and Zn-EpPorTMV are indeed taken up by B16F10 melanoma cells, with loading into the TMV carrier increasing cell uptake of Zn-EpPor, versus free drug alone. Complementary confocal microscopy of Zn-EpPorTMV confirmed that, after an $8 \mathrm{~h}$ incubation, $\mathrm{Zn}$-EpPor is delivered to cells and dispersed throughout the cytoplasm. The intracellular distribution of the Zn-EpPor drug was consistent with intracellular release of the cargo. We hypothesize that TMV is taken up and trafficked to the endolysosome, as previously reported. ${ }^{28,43}$ The acidic endolysosomal compartment will result in protonation of the TMV's interior carboxylic acid resulting in drug release. Furthermore, it is expected that hydrolyases and proteases within the endolysosome will lead 
to degradation of the proteinaceous nanoparticle, further resulting in release of the $\mathrm{Zn}$ EpPor, which escapes the lysosomes and is dispersed throughout the cytoplasm. ${ }^{43}$

In B16F10 cells, loading of Zn-EpPor into TMV improved cell killing efficacy versus free $\mathrm{Zn}$-EpPor alone. The increased efficacy of Zn-EpPorTMV may be attributed to the increased cell uptake of Zn-EpPor due to its delivery by TMV. Additionally, both free Zn-EpPor and $\mathrm{Zn}$-EpPor TMV performed comparably to previously reported preclinical and clinical photodynamic therapies. In B16F10, phthalocyanine-based drugs had $\mathrm{IC}_{50}$ values between 1.10 and $1.25 \mu \mathrm{M}$, while the Japanese drug Talaporfin had an $\mathrm{IC}_{50}$ of $8.50 \mu \mathrm{M} .{ }^{13} \mathrm{In}$ a range of cell lines, including MCF-7, HeLa, and A2780, porphyrin-based photosensitizers had $\mathrm{IC}_{50}$ values ranging from 0.45 to $5.0 \mu \mathrm{M} \cdot{ }^{19,44,45} \mathrm{Also}$, it is of note that the clinically approved Photofrin is ineffective in pigmented melanoma due to inefficient light penetration in melanin-heavy cells, such as the B16F10 cell line. ${ }^{15}$ Zn-EpPor TMV also shows comparable cell killing to other previously reported VNP-based photodynamic therapies.

Photosensitizers, including $\mathrm{C}_{60}$ and other porphyrin-based sensitizers, have been attached to viral nanoparticles, including bacteriophages Q $\beta$, MS2, and M13. These VNP-based systems also exhibited cell killing efficacy in the nano- to micromolar range. ${ }^{46-50}$ Since the MTT assay can be compromised due to impaired mitochondria, we further confirmed efficacy of both Zn-EpPorTMV and free Zn-EpPor using a LIVE/DEAD assay.

\section{CONCLUSION}

In this study, a small molecule photosensitizer, Zn-EpPor, previously used in antimicrobial photodynamic inactivation studies, ${ }^{31-33}$ was applied as a cancer therapeutic, for the first time. Furthermore, to overcome translational challenges of PDT, such as poor solubility and drug targeting, we formulated the $\mathrm{Zn}$-EpPor drug candidate as a nanoparticle therapeutic using the nucleoprotein components of tobacco mosaic virus (TMV). The drug formulation exhibited a good shelf live, drug release during 1-month storage was not apparent, and the nanoparticles maintained structural integrity. The $\mathrm{IC}_{50}$ was determined as $0.54 \mu \mathrm{M}$ and 0.24 $\mu \mathrm{M}$ for free Zn-EpPor and Zn-EpPor TMV, respectively. Overall, the $\mathrm{IC}_{50}$ indicates that $\mathrm{Zn}$ EpPor shows comparable efficacy compared to previously reported porphyrin-based PDT therapeutics. The Zn-EpPorTMV particle proved to be stable and efficacious in vitro, improving upon the cell targeting, uptake, and killing versus free Zn-EpPor. Based on the biocompatibility and tumor homing properties of TMV, photosensitizer-TMV platforms such as Zn-EpPor TMV may hold promise for application in PDT or combination therapies targeting melanoma or other cancers.

\section{Supplementary Material}

Refer to Web version on PubMed Central for supplementary material.

\section{Acknowledgments}

This work was funded in parts through a grant from the National Science Foundation DMR CAREER 1452257 (to N.F.S.), NCI R25 CA148052 Cancer Pharmacology training grant (to K.L.L.), and NIBIB T32 Training Grant T32 EB007509 (to K.L.L.). 


\section{REFERENCES}

1. Baldea I, Filip AG. Photodynamic therapy in melanoma-an update. J. Physiol. Pharmacol. 2012; 63(2):109-118. [PubMed: 22653896]

2. Balch CM, Gershenwald JE, Soong SJ, Thompson JF, Atkins MB, Byrd DR, Buzaid AC, Cochran AJ, Coit DG, Ding S, Eggermont AM, Flaherty KT, Gimotty PA, Kirkwood JM, McMasters KM, Mihm MC Jr, Morton DL, Ross MI, Sober AJ, Sondak VK. Final version of 2009 AJCC melanoma staging and classification. J. Clin. Oncol. 2009; 27(36):6199-6206. [PubMed: 19917835]

3. Baldea I, Ion RM, Olteanu DE, Nenu I, Tudor D, Filip AG. Photodynamic therapy of melanoma using new, synthetic porphyrins and phthalocyanines as photosensitisers - a comparative study. Clujul Med. 2015; 88(2):175-180. [PubMed: 26528068]

4. Robertson CA, Abrahamse H, Evans D. The in vitro PDT efficacy of a novel metallophthalocyanine (MPc) derivative and established 5-ALA photosensitizing dyes against human metastatic melanoma cells. Lasers Surg. Med. 2010; 42(10):926-936.

5. Haddad R, Blumenfeld A, Siegal A, Kaplan O, Cohen M, Skornick Y, Kashtan H. In vitro and in vivo effects of photodynamic therapy on murine malignant melanoma. Ann. Surg. Onc. 1998; 5(3): 241-247.

6. Teng IT, Chang YJ, Wang LS, Lu HY, Wu LC, Yang CM, Chiu CC, Yang CH, Hsu SL, Ho JA. Phospholipid-functionalized mesoporous silica nanocarriers for selective photodynamic therapy of cancer. Biomaterials. 2013; 34(30):7462-7470. [PubMed: 23810081]

7. Szurko A, Kramer-Marek G, Widel M, Ratuszna A, Habdas J, Kus P. Photodynamic effects of two water soluble porphyrins evaluated on human malignant melanoma cells in vitro. Acta Biochim. Pol. 2003; 50(4):1165-1174. [PubMed: 14740003]

8. Agostinis P, Berg K, Cengel KA, Foster TH, Girotti AW, Gollnick SO, Hahn SM, Hamblin MR, Juzeniene A, Kessel D, Korbelik M, Moan J, Mroz P, Nowis D, Piette J, Wilson BC, Golab J. Photodynamic therapy of cancer: an update. Ca-Cancer J. Clin. 2011; 61(4):250-281. [PubMed: 21617154]

9. Broekgaarden M, Weijer R, van Gulik TM, Hamblin MR, Heger M. Tumor cell survival pathways activated by photodynamic therapy: a molecular basis for pharmacological inhibition strategies. Cancer Metastasis Rev. 2015; 34(4):643-690. [PubMed: 26516076]

10. Dougherty TJ, Gomer CJ, Henderson BW, Jori G, Kessel D, Korbelik M, Moan J, Peng Q. Photodynamic therapy. J. Natl. Cancer Inst. 1998; 90(12):889-905. [PubMed: 9637138]

11. Huang Z. A review of progress in clinical photodynamic therapy. Technol. Cancer Res. Treat. 2005; 4(3):283-293. [PubMed: 15896084]

12. Dolmans DE, Fukumura D, Jain RK. Photodynamic therapy for cancer. Nat. Rev. Cancer. 2003; 3(5):380-387. [PubMed: 12724736]

13. Obata T, Mori S, Suzuki Y, Kashiwagi T, Tokunaga E, Shibata N, Tanaka M. Photodynamic Therapy Using Novel Zinc Phthalocyanine Derivatives and a Diode Laser for Superficial Tumors in Experimental Animals. J. Cancer Ther. 2015; 6:53-61.

14. Pavani C, Uchoa AF, Oliveira CS, Iamamoto Y, Baptista MS. Effect of zinc insertion and hydrophobicity on the membrane interactions and PDT activity of porphyrin photosensitizers. Photochem. Photobiol. Sci. 2009; 8(2):233-240. [PubMed: 19247516]

15. Woodburn KW, Fan Q, Kessel D, Luo Y, Young SW. Photodynamic therapy of B16F10 murine melanoma with lutetium texaphyrin. J. Invest. Dermatol. 1998; 110(5):746-751. [PubMed: 9579539]

16. Nwogu C, Pera P, Bshara W, Attwood K, Pandey R. Photodynamic therapy of human lung cancer xenografts in mice. J. Surg. Res. 2016; 200(1):8-12. [PubMed: 26494011]

17. Aggarwal N, Santiago AM, Kessel D, Sloane BF. Photodynamic therapy as an effective therapeutic approach in MAME models of inflammatory breast cancer. Breast Cancer Res. Treat. 2015; 154:251. [PubMed: 26502410]

18. Cheng Y, Cheng H, Jiang C, Qiu X, Wang K, Huan W, Yuan A, Wu J, Hu Y. Perfluorocarbon nanoparticles enhance reactive oxygen levels and tumour growth inhibition in photodynamic therapy. Nat. Commun. 2015; 6:8785. [PubMed: 26525216] 
19. Antoni PM, Naik A, Albert I, Rubbiani R, Gupta S, Ruiz-Sanchez P, Munikorn P, Mateos JM, Luginbuehl V, Thamyongkit P, Ziegler U, Gasser G, Jeschke G, Spingler B. (Metallo)porphyrins as potent phototoxic anti-cancer agents after irradiation with red light. Chem. - Eur. J. 2015; 21(3): 1179-1183. [PubMed: 25421757]

20. Lucky SS, Soo KC, Zhang Y. Nanoparticles in photodynamic therapy. Chem. Rev. 2015; 115(4): 1990-2042. [PubMed: 25602130]

21. Danhier F, Feron O, Preat V. To exploit the tumor microenvironment: Passive and active tumor targeting of nanocarriers for anti-cancer drug delivery. J. Controlled Release. 2010; 148(2):135146.

22. Manchester M, Singh P. Virus-based nanoparticles (VNPs): platform technologies for diagnostic imaging. Adv. Drug Delivery Rev. 2006; 58(14):1505-1522.

23. Singh P, Prasuhn D, Yeh RM, Destito G, Rae CS, Osborn K, Finn MG, Manchester M. Biodistribution, toxicity and pathology of cowpea mosaic virus nanoparticles in vivo. J. Controlled Release. 2007; 120(1-2):41-50.

24. Pokorski JK, Steinmetz NF. The art of engineering viral nanoparticles. Mol. Pharmaceutics. 2011; 8(1):29-43.

25. Bruckman MA, Steinmetz NF. Chemical modification of the inner and outer surfaces of Tobacco Mosaic Virus (TMV). Methods Mol. Biol. 2014; 1108:173-185. [PubMed: 24243249]

26. Bruckman MA, Kaur G, Lee LA, Xie F, Sepulveda J, Breitenkamp R, Zhang X, Joralemon M, Russell TP, Emrick T, Wang Q. Surface modification of tobacco mosaic virus with "click" chemistry. Chem Bio Chem. 2008; 9(4):519-523.

27. Lee KL, Hubbard LC, Hern S, Yildiz I, Gratzl M, Steinmetz NF. Shape matters: the diffusion rates of TMV rods and CPMV icosahedrons in a spheroid model of extracellular matrix are distinct. Biomater. Sci. 2013; 1(6):581.

28. Shukla S, Eber FJ, Nagarajan AS, DiFranco NA, Schmidt N, Wen AM, Eiben S, Twyman RM, Wege C, Steinmetz NF. The Impact of Aspect Ratio on the Biodistribution and Tumor Homing of Rigid Soft-Matter Nanorods. Adv. Healthcare Mater. 2015; 4(6):874-882.

29. Wu M, Shi J, Fan D, Zhou Q, Wang F, Niu Z, Huang Y. Biobehavior in normal and tumor-bearing mice of tobacco mosaic virus. Biomacromolecules. 2013; 14(11):4032-4037. [PubMed: 24093622]

30. Bruckman MA, Randolph LN, VanMeter A, Hern S, Shoffstall AJ, Taurog RE, Steinmetz NF. Biodistribution, pharmacokinetics, and blood compatibility of native and PEGylated tobacco mosaic virus nano-rods and -spheres in mice. Virology. 2014; 449:163-73. [PubMed: 24418549]

31. Feese E, Sadeghifar H, Gracz HS, Argyropoulos DS, Ghiladi RA. Photobactericidal porphyrincellulose nanocrystals: synthesis, characterization, and antimicrobial properties. Biomacromolecules. 2011; 12(10):3528-3539. [PubMed: 21838250]

32. Carpenter BL, Scholle F, Sadeghifar H, Francis AJ, Boltersdorf J, Weare WW, Argyropoulos DS, Maggard PA, Ghiladi RA. Synthesis, Characterization, and Antimicrobial Efficacy of Photomicrobicidal Cellulose Paper. Biomacromolecules. 2015; 16(8):2482-2492. [PubMed: 26181636]

33. Carpenter BL, Feese E, Sadeghifar H, Argyropoulos DS, Ghiladi RA. Porphyrin-cellulose nanocrystals: a photobactericidal material that exhibits broad spectrum antimicrobial activity. Photochem. Photobiol. 2012; 88(3):527-536. [PubMed: 22360680]

34. Leberman R. The isolation of plant viruses by means of "simple" coacervates. Virology. 1966; 30(3):341-347. [PubMed: 5921640]

35. Demir M, Stowell MHB. A chemoselective biomolecular template for assembling diverse nanotubular materials. Nanotechnology. 2002; 13(4):541-544.

36. Czapar AE, Zheng YR, Riddell IA, Shukla S, Awuah SG, Lippard SJ, Steinmetz NF. Tobacco mosaic virus delivery of phenanthriplatin for cancer therapy. ACS Nano. 2016

37. Feese, E. Development of Novel Photosensitizers for Photodynamic Inactivation of Bacteria. Raleigh, NC: North Carolina State University; 2012. p. xxip. 282

38. Niedre M, Patterson MS, Wilson BC. Direct near-infrared luminescence detection of singlet oxygen generated by photodynamic therapy in cells in vitro and tissues in vivo. Photochem. Photobiol. 2002; 75(4):382-391. [PubMed: 12003128] 
39. Moan J, Berg K. The photodegradation of porphyrins in cells can be used to estimate the lifetime of singlet oxygen. Photochem. Photobiol. 1991; 53(4):549-553. [PubMed: 1830395]

40. Castano AP, Demidova TN, Hamblin MR. Mechanisms in photodynamic therapy: part onephotosensitizers, photochemistry and cellular localization. Photodiagn. Photodyn. Ther. 2004; 1(4):279-293.

41. Liu Y, Peterson DA, Kimura H, Schubert D. Mechanism of cellular 3-(4,5-dimethylthiazol-2yl)-2,5-diphenyltetrazolium bromide (MTT) reduction. J. Neurochem. 1997; 69(2):581-593. [PubMed: 9231715]

42. Mosmann T. Rapid colorimetric assay for cellular growth and survival: application to proliferation and cytotoxicity assays. J. Immunol. Methods. 1983; 65(1-2):55-63. [PubMed: 6606682]

43. Wen AM, Infusino M, De Luca A, Kernan DL, Czapar AE, Strangi G, Steinmetz NF. Interface of physics and biology: engineering virus-based nanoparticles for biophotonics. Bioconjugate Chem. 2015; 26(1):51-62.

44. Tachikawa S, El-Zaria ME, Inomata R, Sato S, Nakamura H. Synthesis of protoporphyrin-lipids and biological evaluation of micelles and liposomes. Bioorg. Med. Chem. 2014; 22(17):47454751. [PubMed: 25066052]

45. Rangasamy S, Ju H, Um S, Oh DC, Song JM. Mitochondria and DNA Targeting of 5,10,15,20Tetrakis(7-sulfonatobenzo[b]thiophene) Porphyrin-Induced Photodynamic Therapy via Intrinsic and Extrinsic Apoptotic Cell Death. J. Med. Chem. 2015; 58(17):6864-74. [PubMed: 26295496]

46. Stephanopoulos N, Tong GJ, Hsiao SC, Francis MB. Dual-surface modified virus capsids for targeted delivery of photodynamic agents to cancer cells. ACS Nano. 2010; 4(10):6014-6020. [PubMed: 20863095]

47. Rhee JK, Baksh M, Nycholat C, Paulson JC, Kitagishi H, Finn MG. Glycan-targeted virus-like nanoparticles for photodynamic therapy. Biomacromolecules. 2012; 13(8):2333-2338. [PubMed: 22827531]

48. Gandra N, Abbineni G, Qu X, Huai Y, Wang L, Mao C. Bacteriophage bionanowire as a carrier for both cancer-targeting peptides and photosensitizers and its use in selective cancer cell killing by photodynamic therapy. Small. 2013; 9(2):215-221. [PubMed: 23047655]

49. Cohen BA, Bergkvist M. Targeted in vitro photodynamic therapy via aptamer-labeled, porphyrinloaded virus capsids. J. Photochem. Photobiol., B. 2013; 121:67-74. [PubMed: 23524248]

50. Wen AM, Ryan MJ, Yang AC, Breitenkamp K, Pokorski JK, Steinmetz NF. Photodynamic activity of viral nanoparticles conjugated with C60. Chem. Commun. 2012; 48(72):9044-9046. 
A

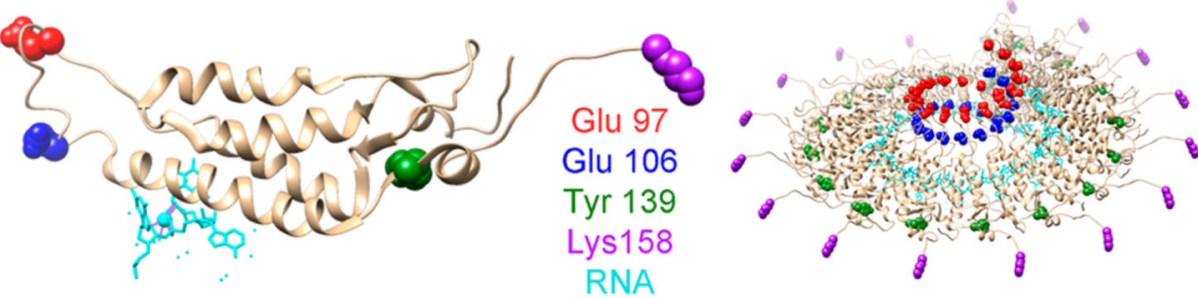

B

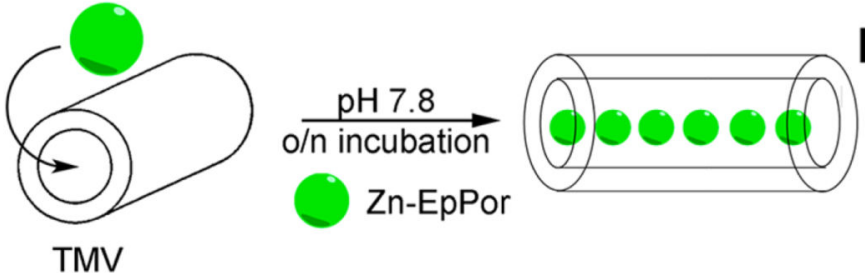

D
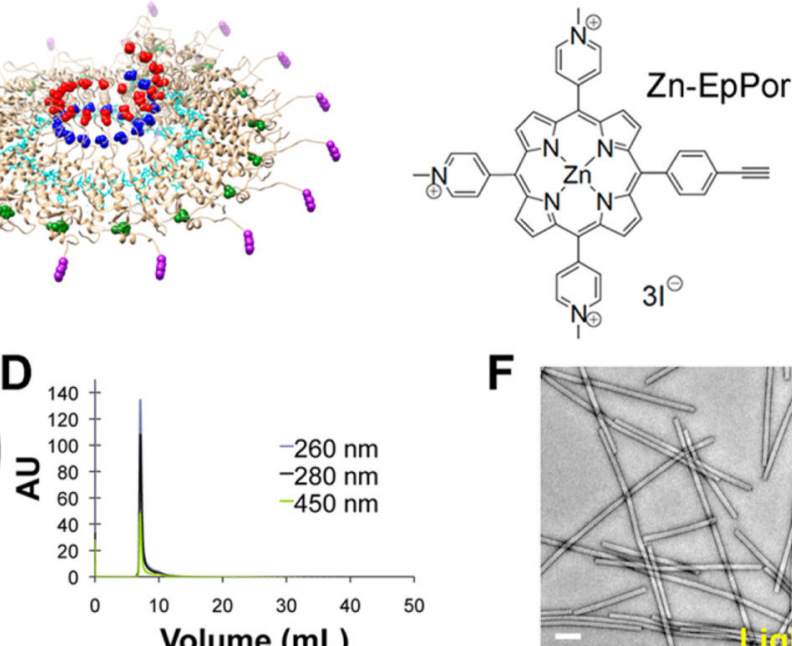

C

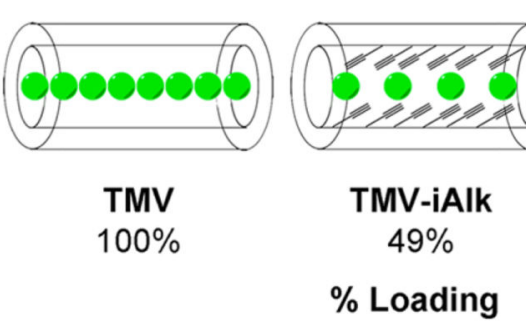

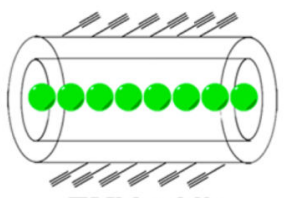

TMV-eAlk

97\%
$E$

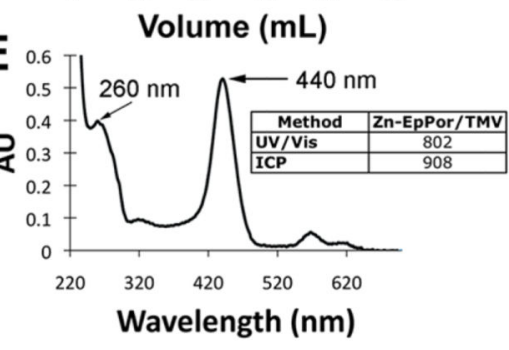

F
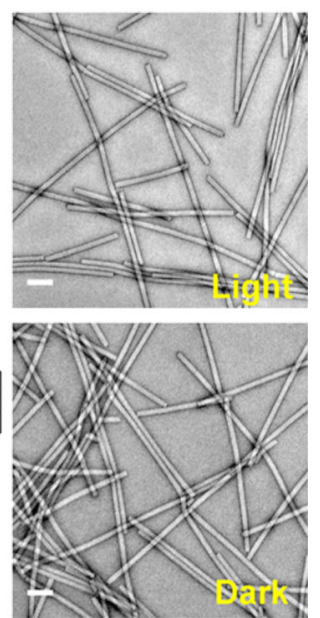

Figure 1.

Zn-EpPor TMV conjugation and characterization. (A) (left) TMV-lysine mutant coat protein (T158K) Glu97 = red, Glu $106=$ blue, Tyr $139=$ green, Lys $158=$ purple, RNA = light blue and (right) Zn-EpPor structure. (B) Schematic of Zn-EpPor loading into TMV. (C)

Schematic of Zn-EpPor loading efficiencies after interior and exterior modification with alkynes at amino acids Glu97 and Glu106 (interior) and Tyr 139 (exterior). (D) Size exclusion chromatography of $\mathrm{Zn}$-EpPor TMV shows coelution of intact TMV (260 and 280 $\mathrm{nm})$ and $\mathrm{Zn}$-EpPor specific absorbance $(450 \mathrm{~nm})$ at the retention time of $8 \mathrm{~mL}$. (E) UV/ visible spectroscopy of $\mathrm{Zn}$-EpPor TMV; table inset shows quantification of $\mathrm{Zn}$-EpPor loading comparing UV/visible spectroscopy and ICP-OES measurements. (F) Negatively stained TEM images of $\mathrm{Zn}$-EpPor TMV after light exposure for $30 \mathrm{~min}$ (top) and corresponding dark control (bottom). 
A
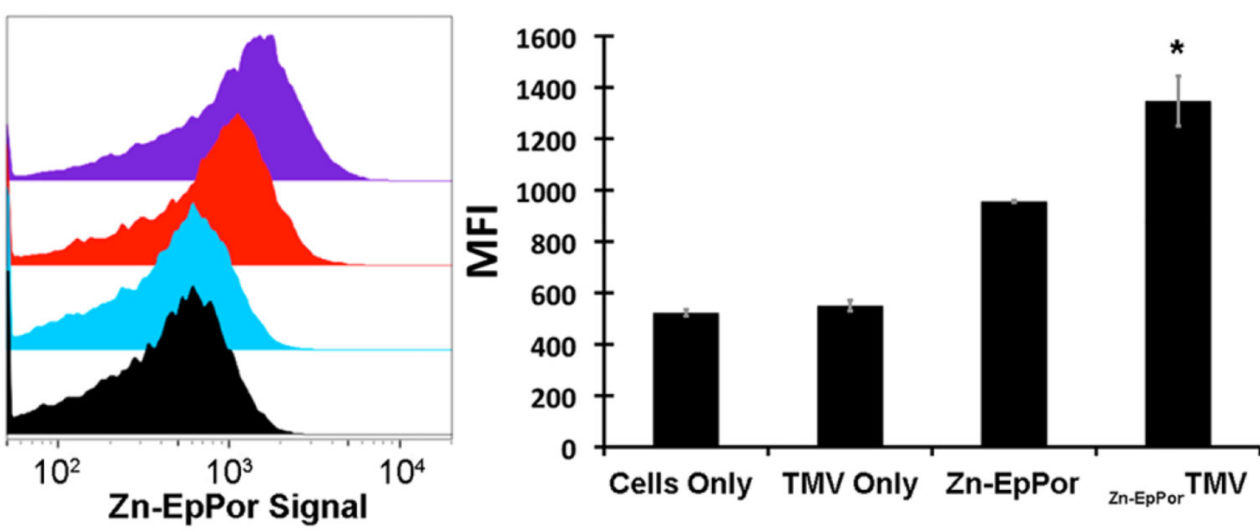

B
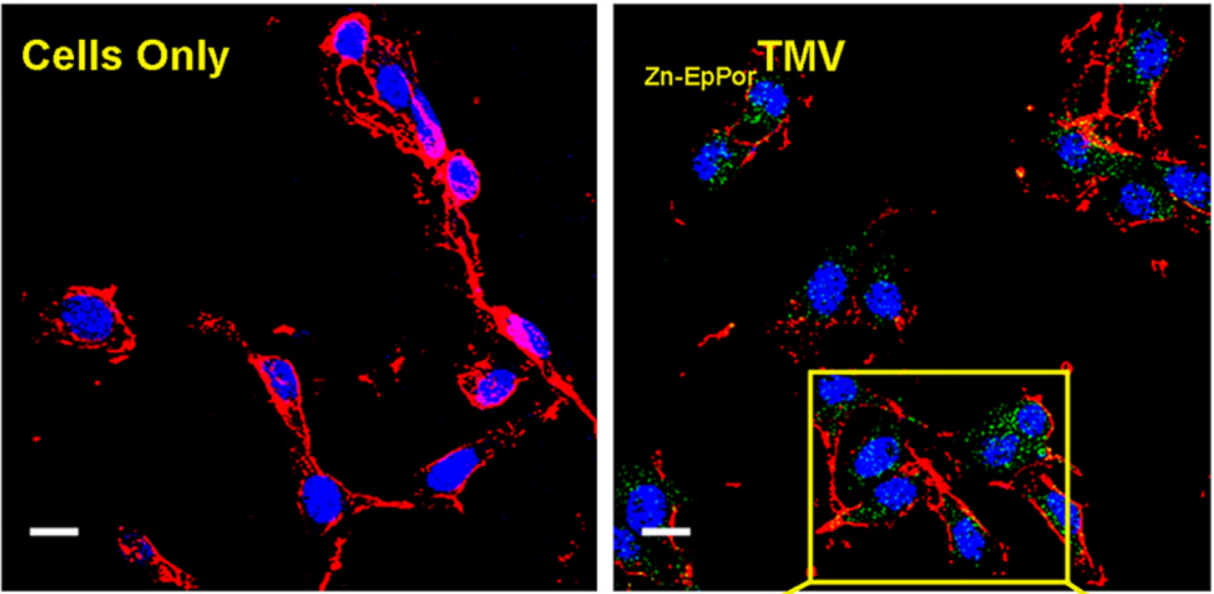

\section{Nuclei Membrane Zn-EpPor TMV}

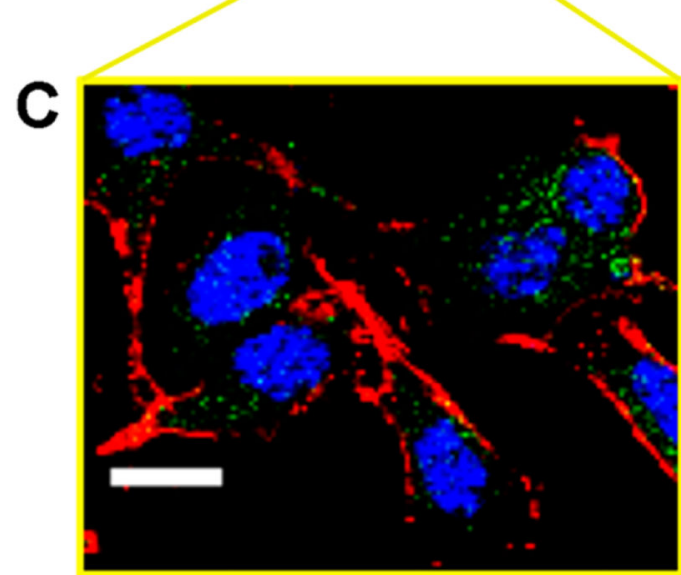

Figure 2.

Zn-EpPorTMV interaction with B16F10 melanoma cells. (A) Zn-EpPorTMV particles $\left(1 \times 10^{5}\right.$ particles/cell) or the corresponding amount of free Zn-EpPor or native TMV were incubated with B16F10 cells for $8 \mathrm{~h}$ and analyzed using flow cytometry. (left) Representative histograms. (right) Statistical analysis (triplicates) and quantitative data show mean fluorescence intensity (MFI) of $\mathrm{Zn-EpPor}$ TMV vs free Zn-EpPor vs unlabeled TMV vs cells only control, $* p<0.05$. (B, C) Confocal microscopy indicates cellular uptake 
of Zn-EpPorTMV (green). Nuclei are stained with DAPI (blue), and membranes are labeled with wheat germ agglutinin (red). Scale bar $=10 \mu \mathrm{m}$. 

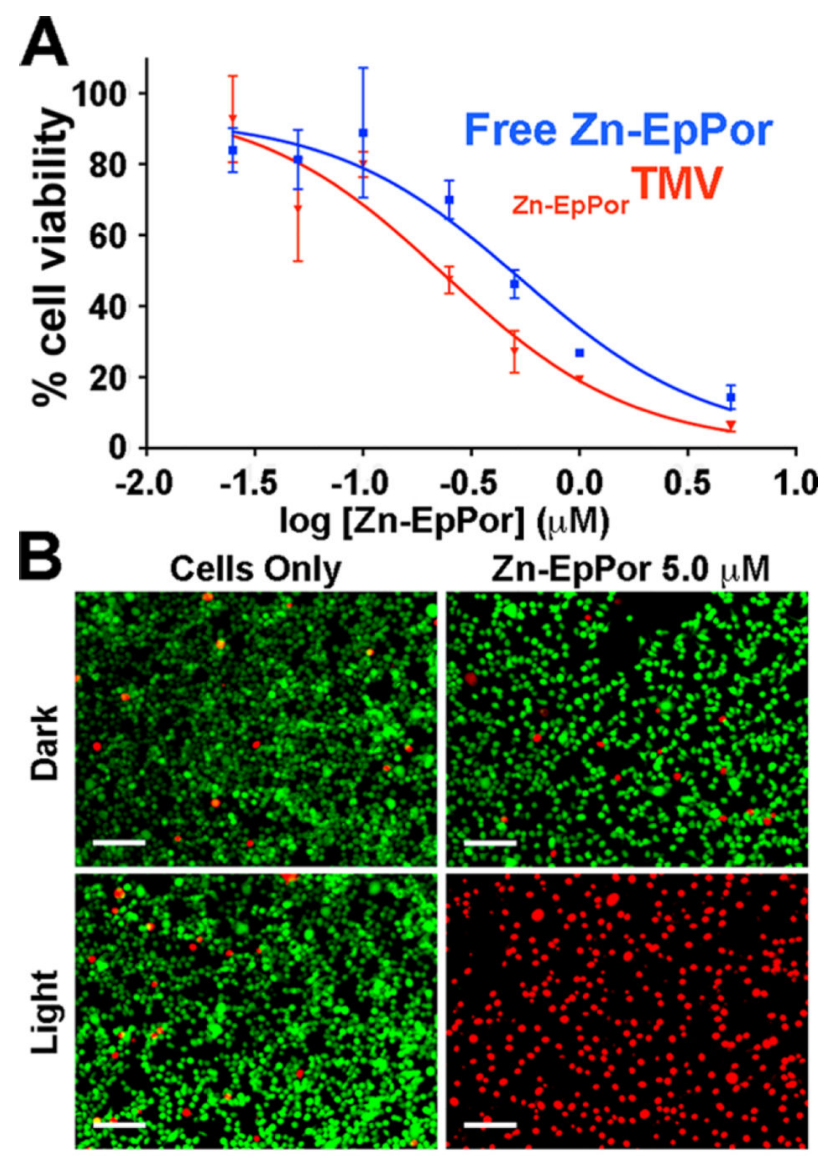
Zn-EpPor $5.0 \mu \mathrm{M}$
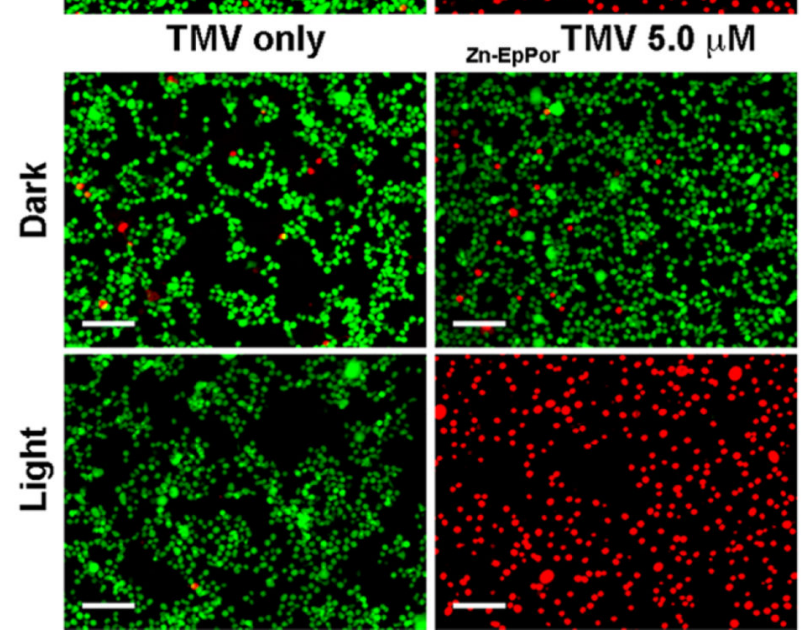

Figure 3.

B16F10 response to Zn-EpPorTMV and free Zn-EpPor. (A) Cell viability following $8 \mathrm{~h}$ incubation with increasing doses of Zn-EpPor or Zn-EpPorTMV and 30 min illumination with white light (no cell killing was observed when cells were incubated in the dark, not shown). (B) Representative LIVE/DEAD images of B16F10 cells incubated with $5.0 \mu \mathrm{M}$ free ZnEpPor or Zn-EpPorTMV. Cells only, TMV only, and dark controls exhibit no cell killing. 
Green = live cells, stained with calcein AM; red = dead cells, stained with ethidium homodimer-1; scale bar $=200 \mu \mathrm{m}$. 